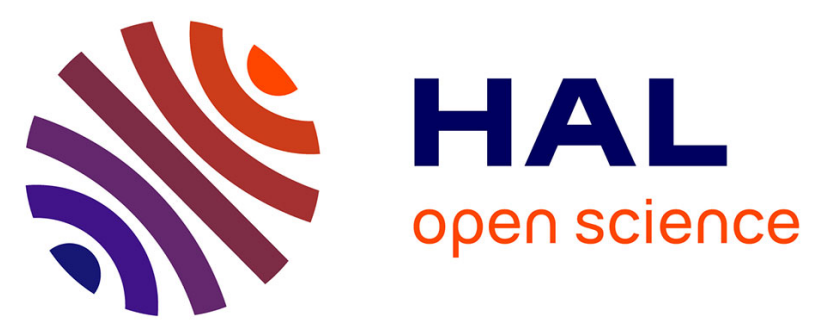

\title{
Dependence of the cellular internalization and transfection efficiency on the structure and physicochemical properties of cationic detergent/DNA/liposomes
}

David Llères, Jean-Marc Weibel, Denis Heissler, Guy Zuber, Guy Duportail, Yves Mély

\section{To cite this version:}

David Llères, Jean-Marc Weibel, Denis Heissler, Guy Zuber, Guy Duportail, et al.. Dependence of the cellular internalization and transfection efficiency on the structure and physicochemical properties of cationic detergent/DNA/liposomes. The Journal of Gene Medicine, 2004, 6 (4), pp.415 - 428. 10.1002/jgm.539 . hal-03027041

\section{HAL Id: hal-03027041 \\ https://hal.science/hal-03027041}

Submitted on 26 Nov 2020

HAL is a multi-disciplinary open access archive for the deposit and dissemination of scientific research documents, whether they are published or not. The documents may come from teaching and research institutions in France or abroad, or from public or private research centers.
L'archive ouverte pluridisciplinaire $\mathbf{H A L}$, est destinée au dépôt et à la diffusion de documents scientifiques de niveau recherche, publiés ou non, émanant des établissements d'enseignement et de recherche français ou étrangers, des laboratoires publics ou privés. 


\section{Dependence of the cellular internalization and transfection efficiency on the structure and physicochemical properties of cationic detergent/DNA/liposomes}

\author{
David Llères ${ }^{1}$ \\ Jean-Marc Weibel ${ }^{2}$ \\ Denis Heissler ${ }^{2}$ \\ Guy Zuber ${ }^{3}$ \\ Guy Duportail ${ }^{1}$ \\ Yves Mély ${ }^{1 *}$ \\ ${ }^{1}$ Laboratoire de Pharmacologie et \\ Physicochimie des Interactions \\ Cellulaires et Moléculaires, UMR \\ 7034 du CNRS, Faculté de \\ Pharmacie, Université Louis Pasteur, \\ B.P. 24, 67401 Illkirch Cedex, France \\ ${ }^{2}$ Laboratoire de Synthèse, Biosynthèse \\ et Activité de Biomolécules, UMR \\ 7123 du CNRS, Faculté de Chimie, \\ Université Louis Pasteur, 1 rue Blaise \\ Pascal, 67008 Strasbourg, France \\ ${ }^{3}$ Laboratoire de Chimie Génétique, \\ UMR 7514 du CNRS, Faculté de \\ Pharmacie, Université Louis Pasteur, \\ B.P. 24, 67401 Illkirch Cedex, France \\ *Correspondence to: Yves Mély, \\ Laboratoire de Pharmacologie et \\ Physicochimie des Interactions \\ Cellulaires et Moléculaires, UMR \\ 7034 du CNRS, Faculté de \\ Pharmacie, Université Louis Pasteur, \\ B.P. 24, 67401 Illkirch Cedex, \\ France. \\ E-mail: mely@pharma.u-strasbg.fr
}

Received: 22 October 2003

Revised: 10 December 2003

Accepted: 17 December 2003

\begin{abstract}
Background Control of the structure and physicochemical properties of DNA complexed with nonviral vectors is essential for efficient biodistribution and gene delivery to cells. Cationic liposomes interact with DNA giving transfection competent but large and heterogeneous aggregates. On the other hand, cationic detergents condense DNA into small homogeneous but reversible complexes inefficient for transfection.
\end{abstract}

Methods In order to combine the favorable features of both vectors, ternary complexes were prepared by adding cationic liposomes to plasmid DNA condensed by cationic detergents. The structure and physicochemical properties of these complexes were investigated by electron microscopy, quasielastic light scattering, gel electrophoresis and fluorescence techniques. These data were then correlated with the transfection efficiency and intracellular trafficking of the ternary complexes determined by luciferase gene expression and confocal microscopy, respectively.

Results The ternary complexes were found to form small, homogeneous, globular, stable and positively charged particles with a highly dense and packed lamellar internal structure differing from the multilamellar structure $\left(L_{\alpha}^{C}\right)$ of the corresponding lipoplexes. In the presence of serum, the ternary complexes were more efficiently internalized into cells, less toxic and showed 20 -fold higher transfection efficiency than lipoplexes.

Conclusions This study showed that small, monodisperse and highly stable complexes could be obtained by precompaction of DNA with cetyltrimethylammonium bromide, followed by addition of cationic lipids. The higher efficiency of the ternary complexes with respect to their corresponding lipoplexes was related to their internal structure which prevents their dissociation by serum proteins and allows efficient internalization in the target cells. Copyright $\odot 2004$ John Wiley \& Sons, Ltd.

Keywords detergent; cationic lipids; fluorescence; confocal microscopy; gene delivery

\section{Introduction}

The success of gene therapy is largely dependent on the development of gene delivery vectors. Nonviral vectors should circumvent some of the 
problems occurring with viral vectors such as endogeneous virus recombination, potential oncogenic effects and unexpected immune response [1,2]. However, in vivo gene delivery steps such as extravasation through fenestrated endothelium [3], diffusion through mucus [4,5] or a tumor mass [6] and the last step into the cytosol are strongly restricted by the size and the stability of the DNA particles $[7,8]$. Synthetic vectors, such as cationic polymers and lipids, interact with DNA through a highly cooperative process, leading to the condensation of the anionic polyelectrolyte. This co-condensation of oppositely charged polymers is a quasi-irreversible process leading to polydisperse microprecipitates containing hundreds of DNA molecules per particle. Complexes are heterogeneous with respect to their composition, size $(50-500 \mathrm{~nm})$, and shape (toroids, rods, and aggregates) [9]. These cationic multimolecular aggregates are efficient for DNA delivery to cells in culture since their large size favors their contact with the cell surface by sedimentation but severely restricts their biodistribution.

In contrast to cationic polymers and lipids, cationic detergents interact with DNA reversibly $[10,11]$. Equilibration ensures monodispersity and entropy tends to direct the system towards the largest number of condensed particles [12]. As a consequence, each particle should ultimately be made of a single nucleic acid molecule. This tendency has been observed experimentally for cationic detergents such as cetyltrimethylammonium bromide (CTAB) [11]. Moreover, detergents show a much higher water solubility than lipids $[11,13]$. Upon addition to cells, we have previously shown that the interaction of CTAB/DNA complexes with the plasma membrane leads to opening of the micelle-like domains, incorporation of CTAB molecules into the lipid bilayer and binding of the decondensed DNA to the membrane $[14,15]$. This may explain the poor transfection efficiency of these complexes. In contrast, interaction with anionic vesicles that mimic the cytoplasmic facing leaflet leads to rapid DNA release [14,15]. Accordingly, the detergents are thought to destabilize the endosomal membrane and induce DNA release into the cytoplasm, in line with the good transfection efficiency observed with complexes of DNA bound to vesicles composed of neutral lipids and cationic detergents [16]. To generate complexes stable enough to reach the cytoplasmic membrane and able to efficiently deliver DNA into the cytoplasm, it was appealing to try to combine the favorable features of cationic detergents and cationic lipids $[13,17]$. To reach this objective, novel ternary detergent/DNA/lipid particles were prepared through a two-step process. Since monomolecular DNA collapse was shown to occur efficiently for detergent concentration below the critical micellar concentration (cmc) [10,11], DNA molecules were first individually condensed with the cationic detergent, CTAB. The resulting particles were then post-complexed by addition of an excess of preformed cationic liposomes. By using quasi-elastic light scattering, electron microscopy, gel electrophoresis and fluorescence techniques, the ternary complexes were found to be small, monodisperse, highly stable and positively charged. Moreover, the particles exhibit a dense and strongly packed lamellar internal structure that differs from the multilamellar structure of the corresponding lipoplexes. In the presence of serum, the transfection efficiency of the ternary complexes analyzed by the expression of a reporter gene was 20-fold higher than that of lipoplexes. Comparison of the intracellular trafficking of ternary complexes and lipoplexes by confocal microscopy showed that the higher level of transfection of the ternary complexes may be due to their lower dissociation onto the cell surface which may be the consequence of their serum-insensitive structure.

\section{Materials and methods}

$N$-(1-(2,3-Dimyristoyloxy)propyl)- $N, N, N$-trimethylammoniumparatoluenesulfonate (DMTAP) (Figure 1) was synthesized as previously described [18], 1,2-dioleoyl-snglycero-3-phosphatidylethanolamine (DOPE), $N$-(1-(2,3dioleoyloxy)propyl)- $N, N, N$-trimethyl ammonium methanesulfonate (DOTAP) (Figure 1), cetyltrimethylammonium bromide (CTAB) (Figure 1), egg yolk phosphatidylcholine (EYPC) and egg yolk phosphatidylDL-glycerol (EYPG) were purchased from Sigma. Ethidium bromide (EtBr), 1,1'-(4,4,8,8-tetramethyl-4,8diazaundecamethylene)bis-4-[[3-methylbenz-1,3-oxazol2-yl]methylidine]-1,4-dihydroquinolinium] tetraiodide (YOYO-1), L- $\alpha$-phosphatidylethanolamine- $N$-(lissamine rhodamine B sulfonyl) (Rh-PE), L- $\alpha$-phosphatidylethanolamine- $N$-(4-nitrobenzo-2-oxa-1,3-diazole) (NBD-PE), and $\mathrm{N}$-(3-triethylammoniumpropyl)-4-(6-(4-(diethylamino) phenyl)hexatrienyl)pyridinium dibromide (FM4-64) were obtained from Molecular Probes.

The pCMV-Luc $(5.5 \mathrm{kbp})$ plasmid was propagated and purified as described [19]. The DNA concentration expressed as mole of bases was determined by absorption spectroscopy, using an extinction coefficient of $6600 \mathrm{M}^{-1} \mathrm{~cm}^{-1}$ at $260 \mathrm{~nm}$ and the plasmid integrity was checked by electrophoresis on $1 \%$ agarose gel.

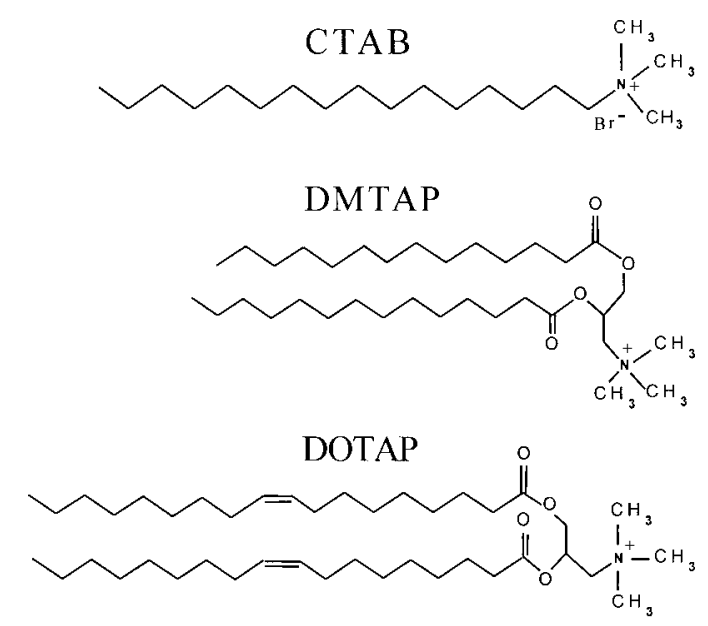

Figure 1. Chemical structures of the cationic detergent and lipids used in this study 


\section{Preparation of liposomes}

Cationic liposomes of DOTAP : DOPE and DMTAP : DOPE were prepared by the film hydration method. Briefly, the lipid mixtures containing DOTAP:DOPE $(1: 1)$ and DMTAP:DOPE $(1: 1)$ were dissolved in chloroform/methanol $(9: 1)$. Solvent was then evaporated under vacuum by rotary evaporation to obtain a thin lipid film. The lipid film was maintained under vacuum for at least $30 \mathrm{~min}$ to remove any residual solvent, and then hydrated with Hepes $15 \mathrm{mM}$, pH 7.4 buffer for $30 \mathrm{~min}$ to achieve a final lipid concentration of $2 \mathrm{mM}$. This preparation was followed by vigorous vortex shaking for 2 min to obtain a solution of multilamellar vesicles (MLV). Before extrusion, MLV were subjected to five freeze/thawing cycles. Large unilamellar vesicles (LUV) were then prepared by extrusion, at $38^{\circ} \mathrm{C}$, of the MLV suspension using a Lipex biomembrane extruder. The size of the filter was first $0.2 \mu \mathrm{m}$ (7 passages) and thereafter $0.1 \mu \mathrm{m}$ (10 passages). LUV made from EYPC and EYPG were prepared according to same procedure. Typically, this procedure generates cationic liposomes with mean diameters of $100-110 \mathrm{~nm}$. The lipid concentration expressed as mole of phosphates was determined spectrophotometrically according to Bartlett [20].

\section{Preparation of lipoplexes}

Binary liposome/DNA complexes defined as lipoplexes [21] were prepared by adding the desired amount of cationic liposomes from a $2 \mathrm{mM}$ stock solution diluted in $150 \mu \mathrm{l}$ Hepes $15 \mathrm{mM}, \mathrm{NaCl} 150 \mathrm{mM}$ pH 7.4 buffer to an equal volume containing $6 \mu \mathrm{g}$ pCMV-Luc plasmid DNA. The two solutions were quickly mixed and incubated at room temperature for $20 \mathrm{~min}$ before further characterization. The final concentration of DNA, expressed in phosphate groups, is $60 \mu \mathrm{M}$. The ratio of cationic lipids to DNA phosphate groups is designated by $r$. Labelled lipoplexes were prepared by mixing $0.5 \mathrm{~mol} \%$ Rh-PE with nonlabelled lipids during the preparation of the liposomes.

\section{Preparation of detergent/DNA/lipid ternary complexes}

The desired amount of monocationic CTAB detergent from a $2 \mathrm{mM}$ stock solution diluted in $75 \mu \mathrm{l}$ Hepes $15 \mathrm{mM}, \mathrm{NaCl} 150 \mathrm{mM} \mathrm{pH} 7.4$ buffer was added to a $75 \mu \mathrm{l}$ solution containing $6 \mu \mathrm{g}$ of pCMV-Luc plasmid DNA under constant stirring. The two solutions were quickly mixed and incubated at room temperature for $10 \mathrm{~min}$. Thereafter, the sample was mixed with $54 \mu \mathrm{l}$ of DMTAP:DOPE (1:1) liposomes from a $2 \mathrm{mM}$ stock solution diluted in a final volume of $150 \mu \mathrm{l}$ Hepes $15 \mathrm{mM}$, $\mathrm{NaCl} 150 \mathrm{mM}$ pH 7.4 buffer and incubated at room temperature for $20 \mathrm{~min}$ before characterization. The final concentrations of DNA (expressed as phosphate groups) and cationic lipids $(r=6)$ in the ternary complexes are 60 and $360 \mu \mathrm{M}$. The ratio of CTAB molecules to DNA phosphate groups is designated by $r^{\prime}$.

\section{Spectroscopic techniques}

Absorption spectra were recorded on a Cary 400 spectrophotometer. Steady-state fluorescence measurements were performed at $20^{\circ} \mathrm{C}$ with a thermostated SLM 48000 spectrofluorimeter. Steady-state fluorescence anisotropy was measured on a SLM 8000 spectrofluorimeter in the T-format configuration, as previously described [14].

DNA condensation was examined by following the fluorescence signal of EtBr added at a 1:50 molar ratio to a $10 \mu \mathrm{M}$ DNA concentration in Hepes $15 \mathrm{mM}, \mathrm{NaCl}$ $150 \mathrm{mM}, \mathrm{pH}$ 7.4. CTAB and/or cationic liposomes were then added to the EtBr/DNA complexes at different ratios, each ratio being prepared as a separate solution. The excitation and emission wavelengths for $\mathrm{EtBr}$ were 510 and $610 \mathrm{~nm}$, respectively.

\section{Gel electrophoresis}

Samples $(5 \mu \mathrm{l})$ containing $0.4 \mu \mathrm{g}$ pCMV-Luc plasmid DNA were mixed with $4 \mu$ l of sample loading buffer containing $40 \%$ sucrose, $0.25 \%$ bromophenol blue and analyzed by electrophoresis on a 1\% agarose gel in Tris-acetate buffer (40 mM, pH 8). DNA was visualized by staining the gel with EtBr prior to UV transillumination.

\section{Quasi-elastic light-scattering measurements}

The particle size and zeta potential were determined using a Zetamaster 3000 (Malvern Instruments, Paris, France) with the following specifications: sampling time, $30 \mathrm{~s}$; medium viscosity, $1.054 \mathrm{cP}$; refractive index, 1.45 (typical liposome RI); scattering angle, $90^{\circ}$; temperature, $25^{\circ} \mathrm{C}$. Data were analyzed using the multimodal number distribution software included with the instrument. Complexes with measured diameters of less than $500 \mathrm{~nm}$ were found to be monodisperse, with size distributions being of about $30 \%$ of their mean value. Complexes with diameters greater than $500 \mathrm{~nm}$ were generally polydisperse, with larger size distributions. Zeta potentials were measured with the following specifications: sampling time, $30 \mathrm{~s} ; 10$ measurements per sample; medium viscosity, $1.054 \mathrm{cP}$; medium dielectric constant, 80; temperature, $25^{\circ} \mathrm{C}$; beam mode $\mathrm{F}(\mathrm{Ka})=1.5$ (Smoluchowsky).

\section{Transmission electron microscopy}

Lipoplexes and ternary complexes were prepared as described above. Carbon films were prepared by sublimation on freshly cleaved mica and recovered by flotation on $\mathrm{Cu} / \mathrm{Rh}$ grids (300 mesh; Touzard \& Matignon, 
Courtaboeuf, France). After drying overnight, grids were kept on a blotting paper in a Petri dish. Immediately before sample addition, grids were glow-discharged $(110 \mathrm{mV}$, $25 \mathrm{~s}, 25 \mu \mathrm{A})$. A drop $(5 \mu \mathrm{l})$ of sample was left on the grid for $1 \mathrm{~min}$. Complexes were stained with $30 \mu \mathrm{l}$ aq. uranyl acetate $(1 \mathrm{wt} \% / \mathrm{wt})$ for $20 \mathrm{~s}$, and excess liquid was removed with a blotting paper. Observations were performed at $80 \mathrm{kV}$ with a Philips EM 410 transmission electron microscope. The size of the particles was determined by taking into account the length (L) and width (l) of each particle: $((L+l) / 2)$. The sizes of about 20 particles were assessed for each condition.

\section{Lipid mixing assay}

Lipid mixing was monitored by the NBD-PE/Rh-PE energy transfer assay [22]. Labelled anionic liposomes containing each probe at $0.5 \mathrm{~mol} \%$ (in respect to phospholipids) were prepared. The rather high probe concentration induces a close proximity of the dyes in the liposome resulting in the quenching of the NBD-PE fluorescence signal. The lipid mixing/fusion was triggered by the addition of $90 \mu \mathrm{l}$ lipoplexes or ternary complexes to $80 \mu \mathrm{l}$ of fluorescent anionic liposomes from a $500 \mu \mathrm{M}$ stock solution in a quartz cuvette containing Hepes buffer $15 \mathrm{mM}, \mathrm{NaCl} 150 \mathrm{mM} \mathrm{pH} 7.4$ at a final volume of $500 \mu \mathrm{l}$. The probe diffusion/dilution was evidenced by the increase in NBD-PE fluorescence resulting from self-quenching release [23]. The fluorescence intensity at $10 \mathrm{~min}\left(I_{10}\right)$ was used to calculate the percentage of lipid mixing by: $\left(I_{10}-I_{0}\right) /\left(I_{\max }-I_{0}\right) \times 100$, where $I_{0}$ designates the fluorescence intensity before addition of the complexes. The excitation wavelength was $465 \mathrm{~nm}$ and the increase in NBD-PE fluorescence after addition of the complexes was monitored at $517 \mathrm{~nm}$. As a negative control, vesicles composed of DOPC alone were mixed with labelled anionic liposomes under the same conditions as described above. The $I_{\max }$ fluorescence was determined using an equivalent concentration of vesicles containing $0.08 \mathrm{~mol} \%$ of both probes, a concentration that would be reached if lipid mixing would be maximal.

\section{Cell culture and transfection}

Mouse fibroblasts from the L929 strain (American Tissue Culture Collection, Rockville, MD, USA) were plated at $5 \times 10^{4}$ cells/well in a 24-well plate containing Dulbecco's modified Eagle's medium (DMEM, $4.5 \mathrm{~g} / 1$ glucose; Seromed) supplemented with $10 \%$ foetal bovine serum (FBS; Biowhittaker), $1 \mathrm{mM}$ sodium pyruvate (Seromed), $50 \mathrm{IU} / \mathrm{ml}$ penicillin and $50 \mu \mathrm{g} / \mathrm{ml}$ streptomycin (Seromed). Cells were maintained at $37^{\circ} \mathrm{C}$ in a $5 \%$ $\mathrm{CO}_{2}$ humidified atmosphere. At the time of transfection, the medium was removed and $100 \mu \mathrm{l}$ of complexes (corresponding to $2 \mu \mathrm{g}$ of plasmid per well) diluted in $900 \mu \mathrm{l}$ of fresh culture medium (DMEM) in the absence or presence of $10 \%$ FBS were added to the cells. Cells were then incubated at $37^{\circ} \mathrm{C}$ for $3 \mathrm{~h} 30 \mathrm{~min}$. The medium was then removed and replaced with $1 \mathrm{ml}$ of fresh medium supplemented with 10\% FBS. Cells were lysed $24 \mathrm{~h}$ post-transfection, and luciferase gene expression was quantified using a commercial kit (Promega, Cergy Pontoise, France) and a luminometer (Mediators PhL, Wien, Austria). Results were expressed as relative light units (RLU) integrated over $10 \mathrm{~s}$ per milligram of cell protein lysate (RLU/mg of protein) using the bicinchoninic acid assay (Pierce, Paris, France). DOTAP : DOPE/DNA lipoplexes were used as a reference.

\section{Cytotoxicity assays}

Cytotoxicity of ternary complexes was evaluated by the 3-(4,5-dimethyl-2-thiazolyl)-2,5-diphenyltetrazolium bromide (MTT) assay [24]. L929 cells were seeded at a cell density of $5 \times 10^{4}$ cells/well in 24-well plates and incubated for $24 \mathrm{~h}$. Binary or ternary complexes or cationic detergents were added to the cells in the presence or absence of $10 \%$ FBS for $3 \mathrm{~h} 30 \mathrm{~min}$. At the end of the transfection experiments, cells were washed with phosphate-buffered saline (PBS), and $250 \mu \mathrm{l}$ of $0.5 \mathrm{mg} / \mathrm{ml}$ MTT solution in DMEM were added to each well. Plates were incubated for an additional $1 \mathrm{~h}$ at $37^{\circ} \mathrm{C}$. Then, MTTcontaining medium was removed and $100 \mu \mathrm{l}$ of DMSO were added to dissolve the formazan crystals formed by living cells. Absorbance was measured at $535 \mathrm{~nm}$ using a Labsystems iEMS microplate reader.

\section{Confocal microscopy}

For confocal microscopy experiments, cells were cultured on 2-well-chambered cover glass dishes (Lab-Tek, Merck, France) at room temperature. Images were taken 4 and $24 \mathrm{~h}$ post-transfection with a MRC-1024ES (BioRad/Elexience, Verrières-le-Buisson, France) confocal laser scanning imaging system equipped with an Eclipse TE 300 (Nikon) inverted microscope, using a 60× water immersion objective. Excitation of YOYO-labelled DNA and FM4-64 was achieved using an argon/krypton mixed gas laser with 488 and $568 \mathrm{~nm}$ excitation lines, respectively. The resulting fluorescent emissions were observed using a 506-538 and 664-696 nm band pass filter, respectively. Excitation of Rh-PE-labelled complexes was achieved using the $568 \mathrm{~nm}$ excitation line, with the resulting fluorescence observed with a $585 \mathrm{~nm} \mathrm{LP}$ filter. Confocal sections were taken every $0.2 \mu \mathrm{m}$. Digital image recording was performed using the LaserSharp 2.3 software (Bio-Rad).

\section{Results \\ Choice of the lipid for ternary complex formation}

Since in vitro experiments have shown that dioleoyl (DO) and dimyristoyl (DM) chains were the most 
effective for transfection [25,26], we first tested two cationic lipid molecules, the saturated dimyristoyl lipid (DMTAP) and the unsaturated dioleyl compound (DOTAP) in order to select the most appropriate one for forming ternary complexes with cationic detergents (Figure 1). These two lipids were associated with an equimolar amount of phosphatidylethanolamine (DOPE) which favors transfection [27]. Firstly, to compare the gene delivery properties of DMTAP and DOTAP, the transfection efficiencies of the DOTAP : DOPE $(1: 1) / D N A$ and DMTAP : DOPE $(1: 1) / D N A$ lipoplexes were determined on L929 cells using a luciferase assay. The lipoplexes were prepared at various lipid/DNA (+/-) charge ratios, $r$. As shown in Figure 2, the magnitude of gene expression was similar for both types of lipoplexes, being about $6 \times 10^{6} \mathrm{RLU} / \mathrm{mg}$ protein for $r$ values up to 6. In contrast, a significant decrease in gene transfection efficiency was observed for both types of lipoplexes at $r=7$. Secondly, due to the well-known cytotoxicity of detergents [28], it was necessary to check the cellular toxicity of the two types of lipoplexes in order to select the less toxic lipid for ternary complex formation. While the cytotoxicity of the two types of lipoplexes was comparable up to $r=5$, DMTAP:DOPE/DNA lipoplexes appeared significantly less cytotoxic (20\% of death cells) than DOTAP : DOPE/DNA lipoplexes (40\% of dead cells) at $r=6$ (Figure 2). Moreover, at $r=7$, the cytotoxicity of the two types of lipoplexes was found to strongly increase, but the DMTAP-based lipoplexes still appeared less toxic than the DOTAP-based ones.

The size of the complexes also plays an important role in successful gene delivery. In this respect, it is likely that formation of ternary complexes with small size will be favored by using the lipid giving the smallest lipoplexes. To this end, we determined the size of the lipoplexes by quasi-elastic light scattering (QELS). The smallest diameter (between 200-450 nm) was obtained at $r=6$ for DMTAP : DOPE/DNA complexes (Figure 3A). Under the same conditions, the DOTAP:DOPE/DNA lipoplexes exhibited significantly larger diameters $(300-750 \mathrm{~nm}$, data not shown). An additional important parameter for efficient transfection is the surface charge of the complexes. Indeed, positively charged complexes are required for binding to the negatively charged cell surfaces [29]. In this respect, since the zeta potential of complexes formed with a cationic detergent/DNA ratio of 1 or 2 is negative $(-45$ to $-20 \mathrm{mV})[13,17]$, lipoplexes with the highest positive charge surface will be preferable for the formation of positively charged ternary complexes. The zeta potential of DMTAP : DOPE/DNA complexes at $r=6$ was found to exhibit a positive value of $+32 \mathrm{mV}$, significantly larger than the $+26 \mathrm{mV}$ measured for DOTAP:DOPE/DNA complexes. Accordingly, on the basis of these comparative studies, we chose DMTAP (in 1:1 mixture with DOPE) at a charge ratio $r=6$ to form the ternary complexes.
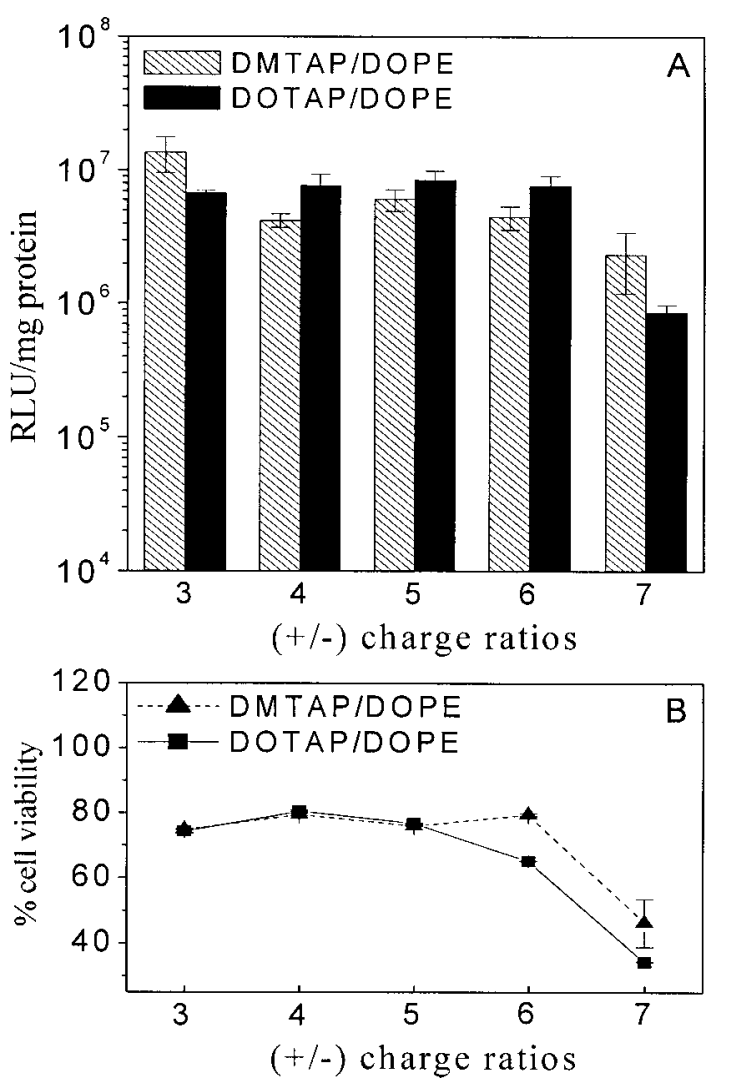

Figure 2. Transfection efficiency and cytotoxicity of two different lipoplexes. (A) Transfection efficiency. L929 cells were transfected with pCMV-Luc ( $2 \mu \mathrm{g} /$ well) complexed with increasing amounts of DOTAP/DOPE (black bars) and DMTAP/DOPE (grey bars). After $3 \mathrm{~h} 30 \mathrm{~min}$, the transfection medium was replaced with fresh culture medium, and cells were cultured for an additional $21 \mathrm{~h}$. Luciferase activity was measured as described in 'Materials and methods'. (B) Cytotoxicity. Cell viability of L929 cells incubated with DOTAP : DOPE/DNA ( $\square$ ) and DMTAP : DOPE/DNA $(\boldsymbol{\Delta})$ complexes as described above was evaluated by determining the total protein amount per well of the transfected cells relative to that of untreated cells. Experiments were carried out in triplicate and error bars indicate standard deviations

\section{Physicochemical characterization of the ternary complexes}

\section{Size and zeta potential measurements}

Ternary CTAB/DNA/DMTAP:DOPE $(1: 1)$ complexes were prepared in two steps. In a first step, the $5.5 \mathrm{kbp}$ plasmid DNA was condensed with CTAB at a given $(+/-)$ charge ratio, $r^{\prime}$, of cationic detergents to DNA phosphates. In a second step, liposomes were added to these detergent/DNA complexes at a ratio $r=6$. Since the size of the complexes is an important parameter for in vivo and in vitro transfection efficiency [30,31], it was determined by QELS and compared with the size of the corresponding lipoplexes. As shown in Figure 3A, the DMTAP : DOPE/DNA lipoplexes form two large and polydisperse populations, peaking at 250 and $450 \mathrm{~nm}$, respectively. Interestingly, a significant and gradual reduction in size as compared with lipoplexes was observed for the ternary complexes prepared with 

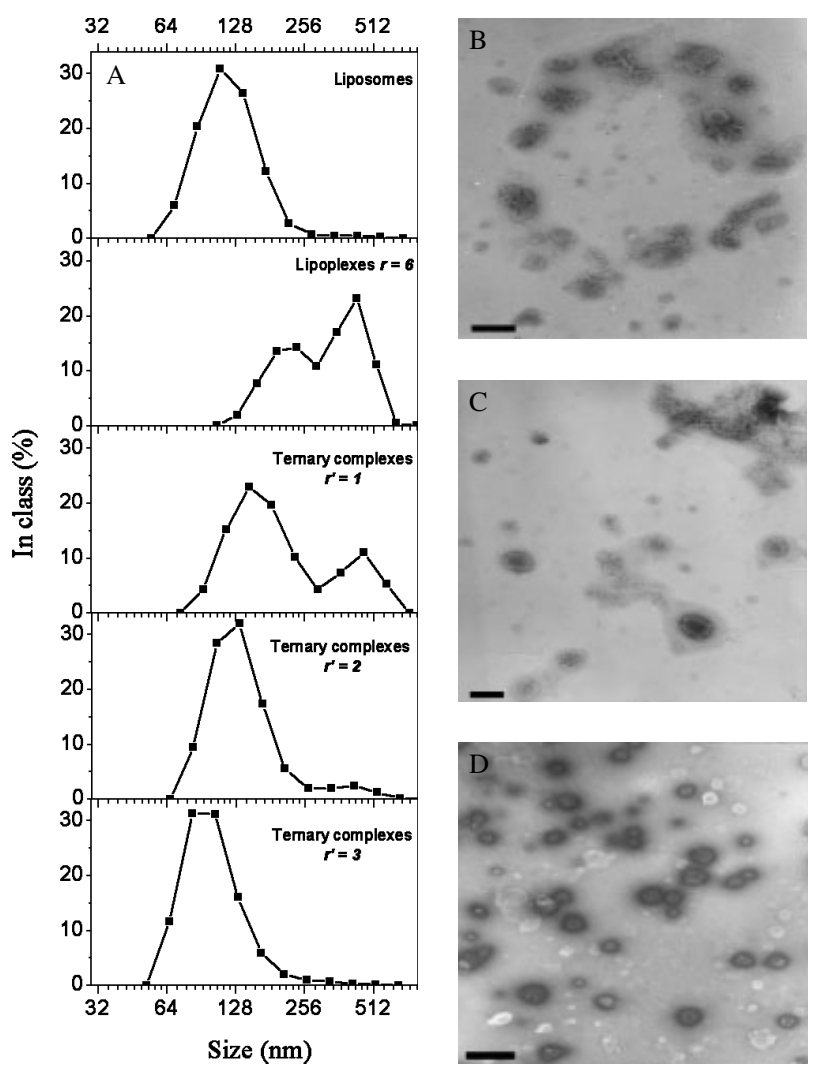

Figure 3. Determination of the size of ternary complexes and lipoplexes. The ternary complexes and lipoplexes were prepared in Hepes $15 \mathrm{mM}, \mathrm{NaCl} 150 \mathrm{mM}, \mathrm{pH} \mathrm{7.4}$. The size of the particles was determined by quasi-elastic light scattering (A) and transmission electron microscopy (B-D). The electron microgrographs in B-D correspond to DMTAP:DOPE/DNA lipoplexes at $r=6$, ternary complexes at $r^{\prime}=1$ and $r^{\prime}=2$, respectively. The bars represent $440 \mathrm{~nm}$

increasing amounts of CTAB. At $r^{\prime}=1$, the population of detergent/DNA/lipid complexes still presented a heterogeneous profile though the peak at $450 \mathrm{~nm}$ significantly decreased to the benefit of the $160 \mathrm{~nm}$ peak. At $r^{\prime}=2$ and 3 , the $450 \mathrm{~nm}$ peak almost disappeared leaving a single narrow population centered at 140 and $90 \mathrm{~nm}$, respectively. These sizes are comparable to the mean diameter $(110 \pm 60 \mathrm{~nm})$ of DMTAP : DOPE $(1: 1)$ cationic liposomes. Noticeably, the size of the ternary complexes remained stable with no aggregation over $24 \mathrm{~h}$ (data not shown). It thus appears that precondensation of DNA with CTAB followed by addition of DMTAP : DOPE $(1: 1)$ liposomes at $r=6$ leads to the formation of small, monodisperse and stable particles.
To confirm the size and dispersity of the ternary complexes and lipoplexes, negative staining transmission electron microscopy was performed. In excellent agreement with QELS measurements, two populations with sizes of $240 \pm 20(n=10)$ and $460 \pm 30 \mathrm{~nm}(\mathrm{n}=10)$ were observed for DMTAP : DOPE/DNA lipoplexes (Figure 3B). Similarly, in the case of ternary complexes at $r^{\prime}=1$, we confirmed that a few large aggregates are being mixed with a population of smaller complexes $(210 \pm 10 \mathrm{~nm}$, $\mathrm{n}=18$; Figure 3C). Finally, ternary complexes at $r^{\prime}=2$ appeared homogeneous with sizes of $120 \pm 10 \mathrm{~nm}(\mathrm{n}=$ 25), in excellent agreement with QELS measurements (Figure 3D).

In a next step, the surface charge of the ternary complexes was characterized by measurement of the zeta potential (Table 1). This parameter was found to strongly depend on the CTAB concentration used for precompaction of the plasmid DNA. Indeed, the surface charge at low $r^{\prime}$ values $(\leq 1)$ was found to be positive, but significantly reduced as compared with that of lipoplexes $(+32 \mathrm{mV})$. In contrast, in the presence of excess CTAB $\left(r^{\prime}=3\right)$, the zeta potential increased up to $+31 \mathrm{mV}$. Due to their positive surface charge, the ternary complexes are thought to interact favorably with the cell membranes.

\section{Agarose gel electrophoresis}

Gel retardation is widely used to assess the formation and stability of complexes between plasmid DNA and gene delivery vectors. First, complexes of plasmid DNA and cationic liposomes were prepared at various charge ratios, $r$, and analyzed by agarose gel electrophoresis (Figure 4). The mobility of the plasmid is retarded as the amount of the DMTAP:DOPE $(1: 1)$ liposomes is increased, demonstrating that the cationic liposomes condense DNA, neutralizing its charge at $r=1$ (Figure 4, lanes 2-5). At $+/-$ ratios exceeding neutralization, the lipoplexes do not enter into the gel and are not dissociated by electrophoresis (Figure 4, lanes 6-8). A similar behavior is observed for the ternary complexes formed by precondensation of DNA with increasing CTAB concentrations followed by addition of DMTAP : DOPE $(1: 1)$ liposomes at a fixed $+/-$ charge ratio, $r=6$ (Figure 4, lanes 9-13). In contrast, CTAB interacts with DNA reversibly. Both components dissociate rapidly and migrate in opposite directions. As a consequence, the mobility of DNA is practically unaffected (Figure 4, lane 14) as compared with DNA alone. These results suggest that ternary complexes are much more stable than CTAB/DNA complexes.

Table 1. Zeta potentials of ternary complexes and lipoplexes ${ }^{\mathrm{a}}$

\begin{tabular}{|c|c|c|c|c|c|}
\hline \multirow[b]{2}{*}{ Complexes } & \multirow[b]{2}{*}{ Lipoplexes } & \multicolumn{4}{|c|}{ Ternary complexes:detergent/DNA/lipid } \\
\hline & & $\begin{array}{c}\mathrm{CTAB} / \mathrm{DNA} \\
r^{\prime}=0.5\end{array}$ & $\begin{array}{c}\mathrm{CTAB} / \mathrm{DNA} \\
r^{\prime}=1\end{array}$ & $\begin{array}{c}\mathrm{CTAB} / \mathrm{DNA} \\
r^{\prime}=2\end{array}$ & $\begin{array}{c}\text { CTAB/DNA } \\
r^{\prime}=3\end{array}$ \\
\hline Zeta potential (mV) & $+32 \pm 3$ & $+18 \pm 2$ & $+24 \pm 1$ & $+26.7 \pm 0.6$ & $+31 \pm 1$ \\
\hline
\end{tabular}

aThe values are expressed as the mean ( \pm standard error) for at least 10 measurements. 


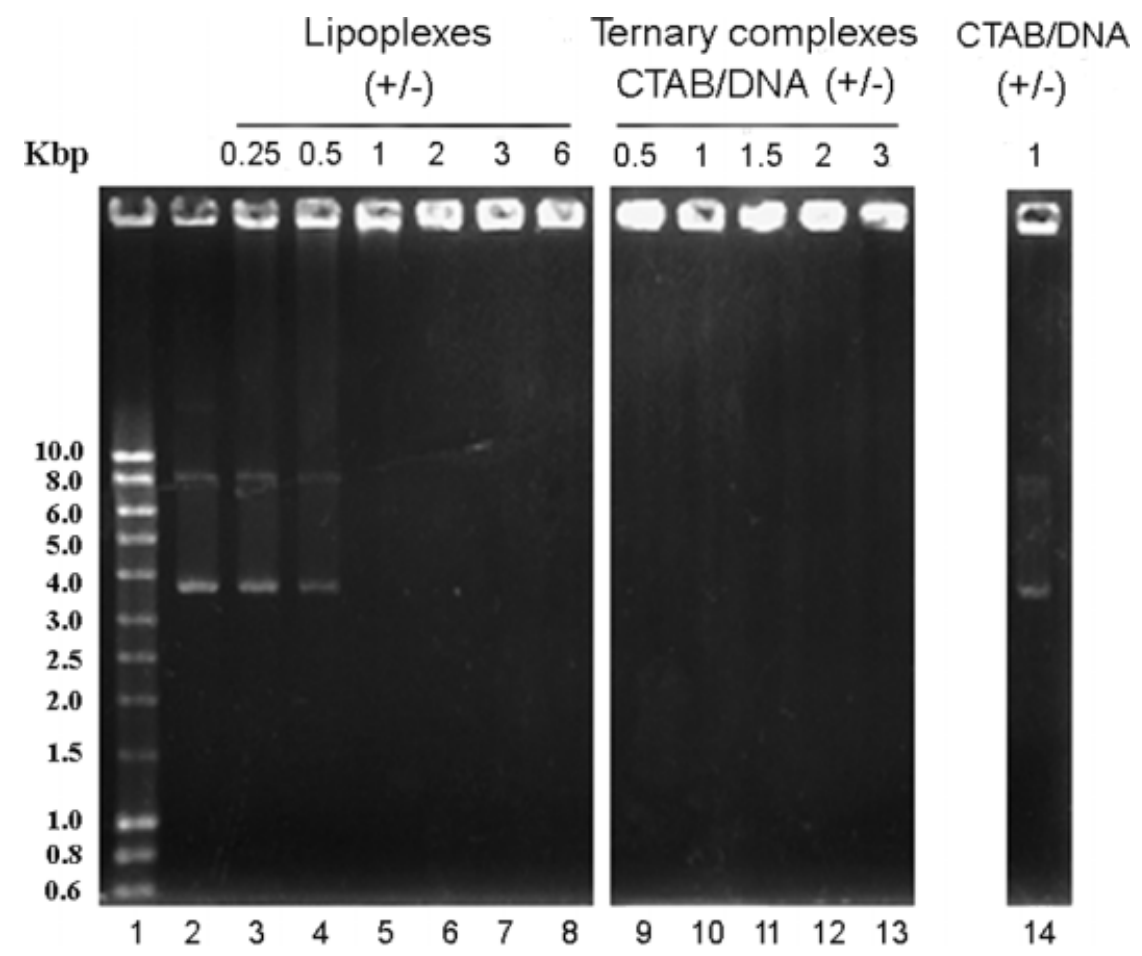

Figure 4. Stability of ternary complexes, lipoplexes and CTAB/DNA complexes. Preparation of the complexes and $1 \%$ agarose gel electrophoresis were performed as described in 'Materials and methods'. $0.4 \mu \mathrm{g}$ of pCMV-Luc plasmid DNA was loaded either in its free form (lane 2) or complexed with the indicated $+/-$ charge ratio, $r$, of DMTAP : DOPE (lanes 3-8) or the indicated charge ratio, $r^{\prime}$, of CTAB/DNA for the ternary complexes (lanes 9-13). Lane 14 corresponds to a complex of DNA with CTAB at $r(+/-)=1$. The molecular weight markers are in lane 1 . Noticeably, the staining of the well of lane 2 is an artefact
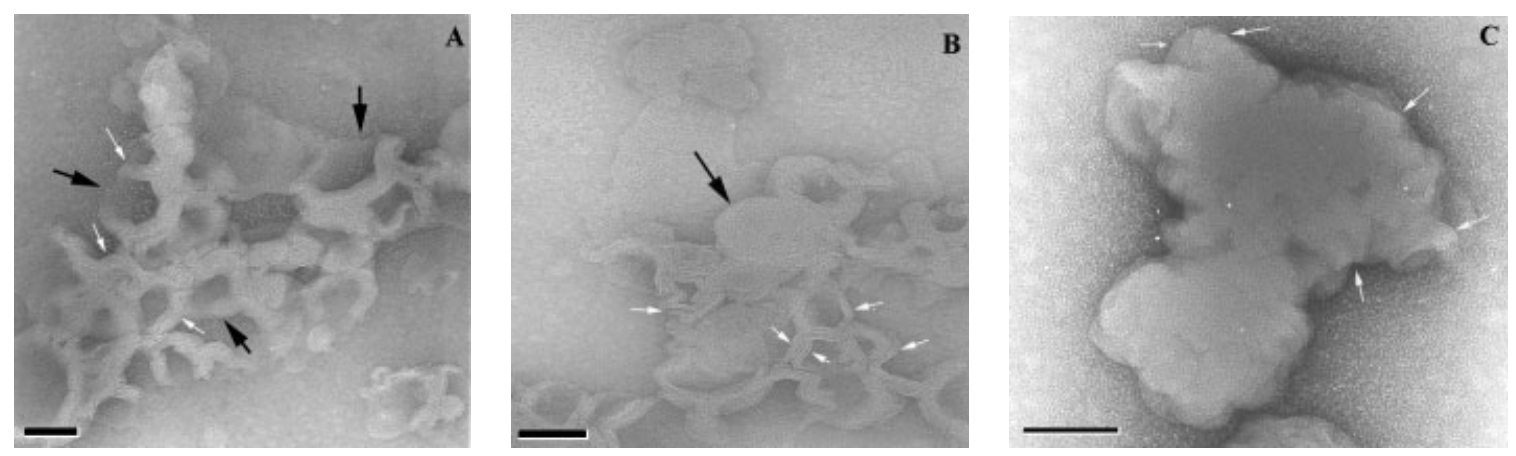

Figure 5. Transmission electron micrographs of DMTAP : DOPE/DNA lipoplexes (A), ternary complexes at $r^{\prime}=1(\mathrm{~B})$ and $r^{\prime}=2$ (C). Notice, in A, the existence of multilamellar ordered structures comprised of alternating layers of two-dimensional arrays of DNA sandwiched between lipid bilayers (white arrows). Black arrows point to macroscopic hexagonal assemblies of the multilamellar ordered structures. In B, the white arrows show hexagonal 'squeletons' constituted by couples of two lamellae separated by a large interlamellar space. The black arrow shows a globular dense particle. In C, the ternary complexes are globular and show a dense and highly bent lamellar structure (white arrows). The bars represent $80 \mathrm{~nm}$

\section{Structural organization of the ternary complexes}

Since the physicochemical parameters (size, stability and surface charge) of complexes used for gene transfection are tightly related to their structural organization [32], the structure of the ternary complexes at different charge ratios, $r^{\prime}$, was investigated by transmission electron microscopy. In the case of DMTAP : DOPE/DNA lipoplexes, we observed polymorphic complexes displaying a multilayered structure (Figure 5A). As indicated by the white arrows, this multilamellar organization consists of at least five lipid bilayers of $4 \mathrm{~nm}$ thickness each, sandwiching plasmid DNA in a $2.5 \mathrm{~nm}$ thick interlamellar space. Moreover, these multilayered structures were found to be organized into macroscopic hexagonal assemblies (black arrows). The general aspect of these multilayered structures as well as the dimensions of both the bilayer and interlamellar thicknesses are fully consistent with the lamellar $L_{\alpha}^{C}$ phase that has been reported for several other lipoplexes [33,34]. In the case of the ternary complexes at $r^{\prime}=1$, the structure of the complexes appears more heterogeneous. A multilamellar organization is retained in some complexes (Figure 5B) but the hexagonal 'squeleton' of these complexes is 
generally characterized by only two couples of two lamellae (white arrows) with a larger interlamellar space (6 instead of $2.5 \mathrm{~nm}$ ) than in lipoplexes, indicating that the DNA molecules occupy a larger volume in these complexes. Additionally, we observe also more globular particles (black arrow) with a high electron density probably caused by accumulation of DNA. These globular particles are also the major particles observed for the ternary complexes at $r^{\prime}=2$ (Figure 5C). As indicated by the white arrows, these particles show a highly bent and packed lamellar organization. Although this organization does not correspond to a lamellar $L_{\alpha}^{C}$ phase, the particles do not also exhibit the lines and circles that characterized the tubes formed in hexagonal phases $[35,36]$. This suggests that CTAB molecules do not induce a transition from a multilamellar to a hexagonal phase.

\section{Interaction of the ternary complexes with model membrane systems}

One critical aspect in the use of gene delivery carriers is the stability of their complexes with DNA. To analyze the intrinsic stability of the ternary complexes, we investigated by using $\mathrm{EtBr}$ intercalation properties, the DNA condensation state during the interaction of the ternary complexes with model membrane vesicles. It has been previously shown that the interaction of the complexes with the external and cytoplasmic leaflets of the plasma membrane could be modelled by using neutral and anionic vesicles, respectively [14,15,37]. Accordingly, the interaction of lipoplexes and ternary complexes with lipid bilayers was investigated by using LUV composed either of EYPC, a dipolar zwitterion with no net charge, or of an equimolar mixture between EYPC and the negatively charged EYPG lipid. With DMTAP : DOPE/DNA lipoplexes, the addition of either neutral or anionic vesicles leads to a $25 \%$ recovery of EtBr fluorescence (Figure 6), suggesting that the interaction with the vesicles induces a limited release of DNA. The incorporation of DOPC instead of DOPE in the lipoplex formulation leads to a significant reduction in the DNA release $(<10 \%$ recovery) confirming that DOPE plays a critical role in the release of DNA during the interaction with membranes. For the ternary CTAB/DNA/DMTAP:DOPE complexes at a charge ratio $r^{\prime}=0.5$, the addition of both types of vesicles induces a DNA exposition slightly reduced as compared with that observed with DMTAP : DOPE/DNA lipoplexes. This suggests that precompaction of DNA with substoichiometric CTAB concentrations leads to a limited stabilization as compared with lipoplexes. In contrast, for ternary complexes prepared at CTAB/DNA ratios greater than or equal to 1 , only a marginal recovery of EtBr fluorescence was seen in the presence of anionic LUV, suggesting that ternary complexes may be highly resistant to destabilization by the cytoplasmic membrane leaflet. The interaction of the ternary complexes with neutral LUV appeared more complex. At a ratio $r^{\prime}=1$, the EtBr fluorescence recovery and thus the dissociation of the ternary complexes were minimal. At higher $r^{\prime}$

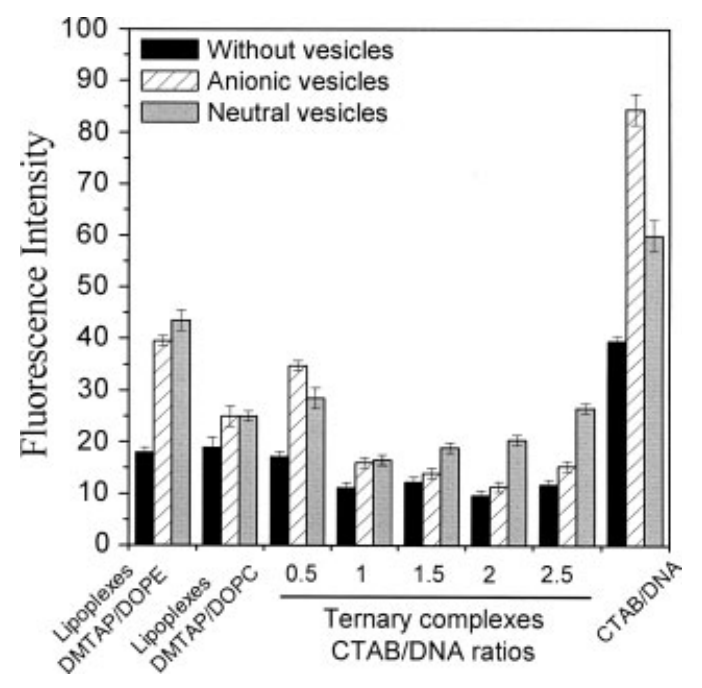

Figure 6. Ethidium bromide (EtBr) intercalation, as followed by its fluorescence intensity, for lipoplexes, ternary complexes and detergent/DNA complexes in the absence and presence of neutral or anionic vesicles. The lipoplexes were prepared at a $(+/-)$ charge ratio $r=6$. The ternary complexes were prepared at the indicated $r^{\prime}$ ratios. The CTAB/DNA complexes were formed at a $(+/-)$ charge ratio of 1

values, the recovery of EtBr fluorescence increased with $r^{\prime}$, suggesting that excess CTAB slightly destabilized the ternary complexes leading to an increase in the level of DNA release during the interaction with the external membrane leaflet. Nevertheless, the stability of the ternary complexes appears much higher than that of CTAB/DNA binary complexes since a large recovery of $\mathrm{EtBr}$ fluorescence was observed for the latter with both types of LUV. In conclusion, the behavior of the ternary complexes with both types of LUV is distinctly different from that of lipoplexes and CTAB/DNA complexes, indicating that they exhibit different stabilities and physicochemical properties.

To gain further insight into the interaction of the ternary complexes with vesicles, the extent of lipid mixing that may result as a consequence of membrane fusion or destabilization was measured using a fluorescence resonance energy transfer (FRET) assay, which is dependent on the dilution of a pair of fluorescent lipids, NBD-PE and Rh-PE [23]. The results obtained when DMTAP : DOPE/DNA lipoplexes or ternary CTAB/DNA/DMTAP : DOPE complexes were mixed with anionic vesicles are presented in Figure 7. A rapid fluorescence increase indicative of fluorescent lipid dilution was observed when lipoplexes were mixed with anionic EYPC/EYPG vesicles. This fluorescence increase corresponded to an extent of lipid mixing of about $20 \%$. In contrast, for ternary complexes, a more limited fluorescence increase, strongly depending on the charge ratio, $r^{\prime}$, was observed. The percentage of lipid mixing varied from $17.5 \%$ for $r^{\prime}=0.5$ to $10 \%$ at $r^{\prime}=3$. As a negative control, mixing of labelled anionic vesicles with unlabelled DOPC vesicles led to a fluorescence increase of only about 4\%. These results showed that the level of lipid 


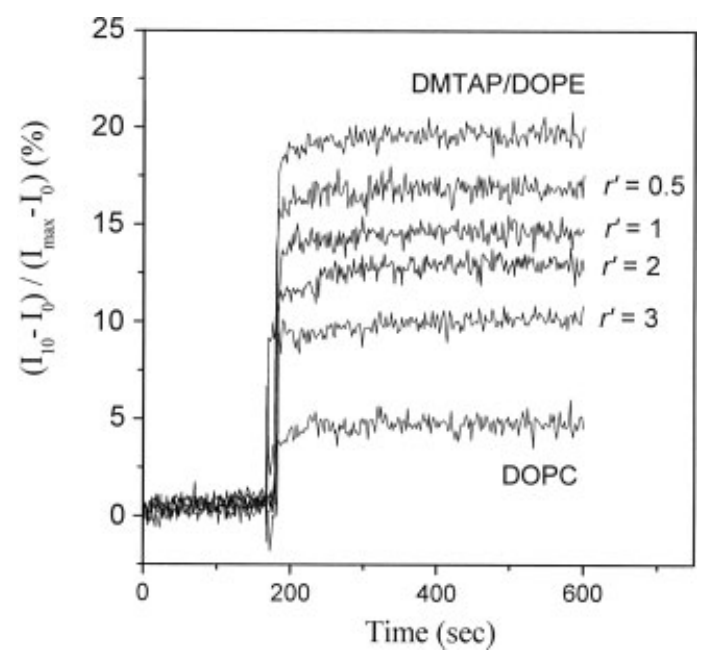

Figure 7. Lipid mixing assay. Lipid mixing of DMTAP : DOPE/ DNA lipoplexes, ternary complexes at various $r^{\prime}$ values and DOPC liposomes after the addition of EYPC/EYPG anionic liposomes. The percentage of lipid mixing has been calculated as (fluorescence intensity $10 \mathrm{~min}$ after anionic liposome addition - intensity at $\left.t_{0}\right) /($ maximum intensity - intensity at $\left.t_{0}\right) \times 100$

mixing is significantly reduced for ternary formulations as compared with lipoplexes, confirming that ternary complexes are resistant to destabilization by vesicles mimicking the cytoplasmic leaflet of the membrane. Nevertheless, since it is not clear whether observed changes in lipid mixing were relevantly correlated to the ability of complexes to transfect cells [38], in vitro transfection experiments were further performed.

\section{In vitro gene transfer activity, toxicity and trafficking of the ternary complexes}

\section{Transfection efficiency and cytotoxicity of ternary complexes}

Ternary complexes were assessed for their in vitro transfection efficiency by monitoring the transient expression of luciferase reporter gene in L929 cells. In serum-free medium, the DMTAP:DOPE/DNA lipoplexes at $r=6$ gave luciferase signals $\left(6 \times 10^{6} \mathrm{RLU} / \mathrm{mg}\right.$ protein, Figure 8) that were about four orders of magnitude larger than those obtained with CTAB/DNA complexes, the latter being only slightly more efficient than naked DNA (data not shown). The ternary complexes showed intermediate transfection efficiencies that decreased with increasing $r^{\prime}$ ratios. In comparison with lipoplexes, the decrease in transfection efficiency was about 5 for $r^{\prime}=0.5$ and reached 70 for $r^{\prime} \geq 1$. Due to cytotoxic effects, no transfection efficiency could be measured at $r^{\prime} \geq 2.5$.

In the presence of $10 \%$ of serum, the transfection efficiency of the lipoplexes was reduced by two orders of magnitude. A similar dramatic decrease was observed for the ternary complexes at the lowest concentration of CTAB $\left(r^{\prime}=0.5\right)$. In sharp contrast, the serum does not change the transfection efficiency of ternary complexes

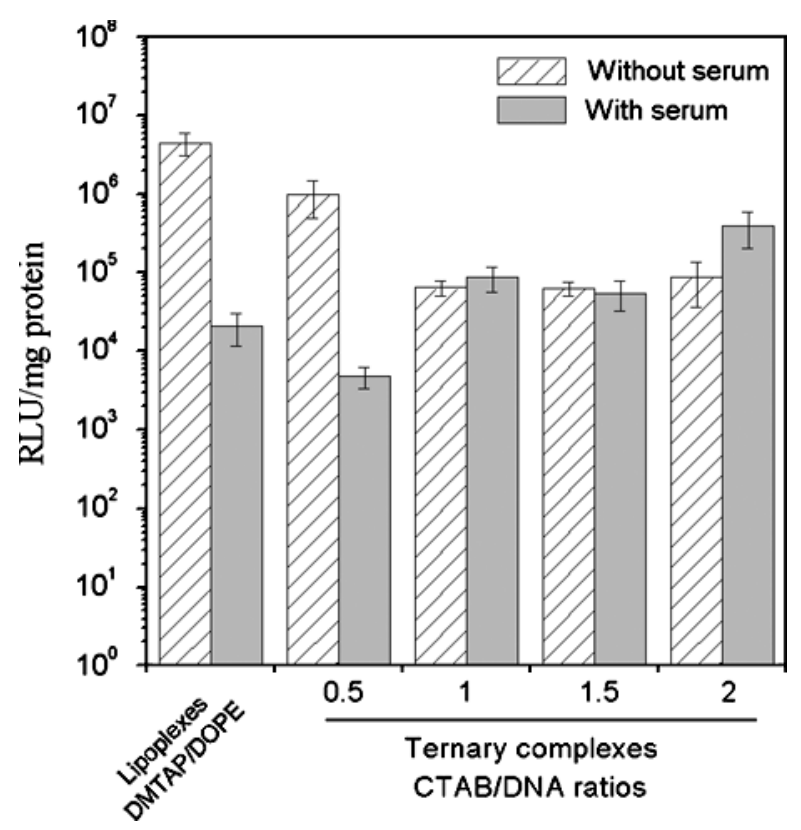

Figure 8. Serum-dependence of the transfection efficiency of the ternary complexes. L929 cells were transfected with ternary complexes at increasing $r^{\prime}$ values or DMTAP : DOPE/DNA lipoplexes at $r=6$, in the absence (hatched bars) or presence (grey bars) of $10 \%$ serum. After $3 \mathrm{~h} 30 \mathrm{~min}$, the transfection medium was replaced with fresh culture medium, and cells were cultured for an additional $21 \mathrm{~h}$. Luciferase activity was measured as described in 'Materials and methods'. Transfections were carried out in triplicate and error bars indicate standard deviations

at $r^{\prime}=1$ or 1.5 , and even induces a slight increase at $r^{\prime}=2$. It transpires that the transfection efficiency of the ternary complexes at the latter ratio was about 20 times higher than the transfection efficiency of lipoplexes. Noticeably, this feature could not be related to an increased sedimentation of the ternary complexes onto the cells $[39,40]$ since size measurements do not show significant differences between ternary complexes and lipoplexes in serum-containing medium (data not shown).

Next, to determine the cytotoxicity of the ternary complexes, a MTT assay was performed. In a serum-free medium, a slight reduction (about 20\%) in the cellular viability was observed for ternary complexes at $r^{\prime}=0.5$ and 1 as compared with DMTAP:DOPE/DNA lipoplexes (Figure 9). In sharp contrast, a dramatic increase in cell mortality was observed for $r^{\prime}=2$, leading to about $80 \%$ of dead cells. Nevertheless, the cytotoxicity of the ternary complexes was significantly less than that of CTAB alone incubated at the concentrations used to prepare the ternary complexes, indicating that a large part of the CTAB molecules were embedded in the ternary complexes and not free in solution.

In the presence of serum, almost no cytotoxicity was observed for ternary complexes, even at a ratio of 2. The protective effect of serum is probably linked to the sequestration of the free CTAB molecules by serum components. It thus appears that the ternary complexes show a good transfection efficiency and a limited cytotoxicity in the presence of serum. 


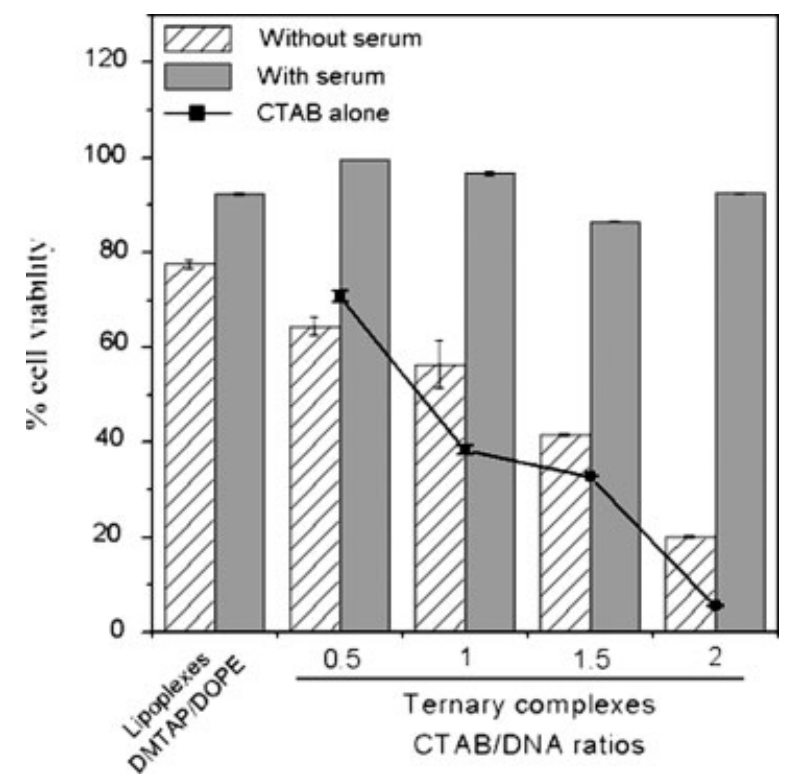

Figure 9. Serum-dependence of the cytotoxicity of the ternary complexes. The ternary complexes and lipoplexes were prepared as in Figure 3 and were incubated with L929 cells in the absence (hatched bars) or presence (grey bars) of $10 \%$ serum. The viability of the L929 cells was determined by the MTT assay after $3 \mathrm{~h} 30 \mathrm{~min}$ incubation with the complexes ( $2 \mu \mathrm{g}$ pCMV-Luc/well) or detergent alone (at the same concentration as that used to prepare the complexes). The viability assay was carried out in triplicate. Error bars indicate standard deviations

\section{Intracellular trafficking of ternary complexes}

In order to further understand the transfection efficiency results both in the absence and presence of serum, we compared the intracellular trafficking of the ternary complexes and lipoplexes by confocal microscopy. The internalization of the ternary complexes and lipoplexes was followed by using both the DNA bis-intercalating dye YOYO-1 (green) and the lipid marker Rh-PE (red). In the case of lipoplexes in the absence of serum, both the green fluorescence of YOYO and the red fluorescence of the Rh-PE lipid formed a dotted intracellular pattern at $4 \mathrm{~h}$ post-transfection, suggesting that both the DNA and the lipids are predominantly internalized in endosomes (Figure 10), in good agreement with recent data on a similar type of lipoplexes [41]. Moreover, co-localization of the two dyes was clearly assessed by the numerous intracellular yellow patches in the overlay images (Figure 10), suggesting that the DNA and the lipids are predominantly localized in the same endosomes and that the lipoplexes are internalized in a nondissociated form. In contrast, only a limited intracellular co-localization of the two fluorophores was observed for the ternary complexes (Figure 10). Indeed, the green fluorescence of YOYO appeared homogeneously distributed on the cell surface, while the red fluorescence from the lipids was extensively diluted in the cell culture medium. This suggests that, in the absence of serum, the ternary complexes were destabilized during their interaction with the cytoplasmic membrane, leading to DNA release onto the cell surface.
In order to further assess the role of endocytosis in the internalization of the lipoplexes and ternary complexes, we incubated L929 cells with YOYO-labelled particles and FM4-64, a marker of membrane endocytosis [42]. The two dyes can be followed simultaneously since the FM4-64 red fluorescence is easily distinguished from the YOYO-1 green fluorescence. In this respect, co-localization of FM4-64 and complexes will yield yellow spots. With the lipoplexes, in the absence of serum, we observed a high density of punctuated yellow dots which grew in number and size with time (data not shown) and accumulated in perinuclear areas at $4 \mathrm{~h}$ post-transfection (Figure 11). These observations confirm that by analogy to PEI/DNA complexes [42], lipoplexes are mainly internalized by endocytosis in L929 cells. In sharp contrast, the green fluorescence for ternary complexes at $r^{\prime}=1$ appeared more diffuse and stayed essentially at the surface of the cytoplasmic membrane even at $4 \mathrm{~h}$ post-transfection. Moreover, no yellow patches were detected in the overlay images, suggesting that, in serum-free medium, only a limited amount of ternary complexes may be internalized by endocytosis in L929 cells. Noticeably, no significant change in the pictures was observed after $24 \mathrm{~h}$ (data not shown).

In the presence of serum, only a marginal internalization of the lipoplexes was observed at $4 \mathrm{~h}$ post-transfection (Figure 11). Moreover, a major part of the lipoplexes appears destabilized onto the cytoplasmic membrane, with a large release of YOYO-labelled DNA onto the cell surface. In contrast, a diffuse intracellular green fluorescence of YOYO-labelled ternary complexes (Figure 11) could be observed at $4 \mathrm{~h}$ post-transfection, indicating a significant internalization of these complexes. Moreover, the limited number of yellow patches suggests that the complexes may be only partly internalized by endocytosis or that the complexes may be rapidly released from the endosomes.

\section{Discussion}

The purpose of this work was to characterize the physicochemical properties of ternary complexes based on CTAB cationic detergents, DMTAP:DOPE $(1: 1)$ cationic liposomes and DNA and understand the relationship between their structure and biological activity. Precompaction of DNA with CTAB, followed by complexation with DMTAP:DOPE $(1: 1)$ liposomes, led to ternary complexes with physicochemical properties and morphologies distinct from those of lipoplexes and CTAB/DNA complexes. At a charge ratio $r^{\prime}(+/-)$ of 2 , ternary complexes formed a homogeneous population of globular particles with a relatively small diameter (about $120 \mathrm{~nm}$, Figure 3) as compared with the heterogeneous population of DMTAP : DOPE/DNA lipoplexes. However, the size of the ternary complexes is significantly larger than the $30 \mathrm{~nm}$ diameter obtained when a $5.5 \mathrm{kbp}$ plasmid DNA was monomolecularly collapsed with detergentbased molecules [13]. This suggests that, as in the 


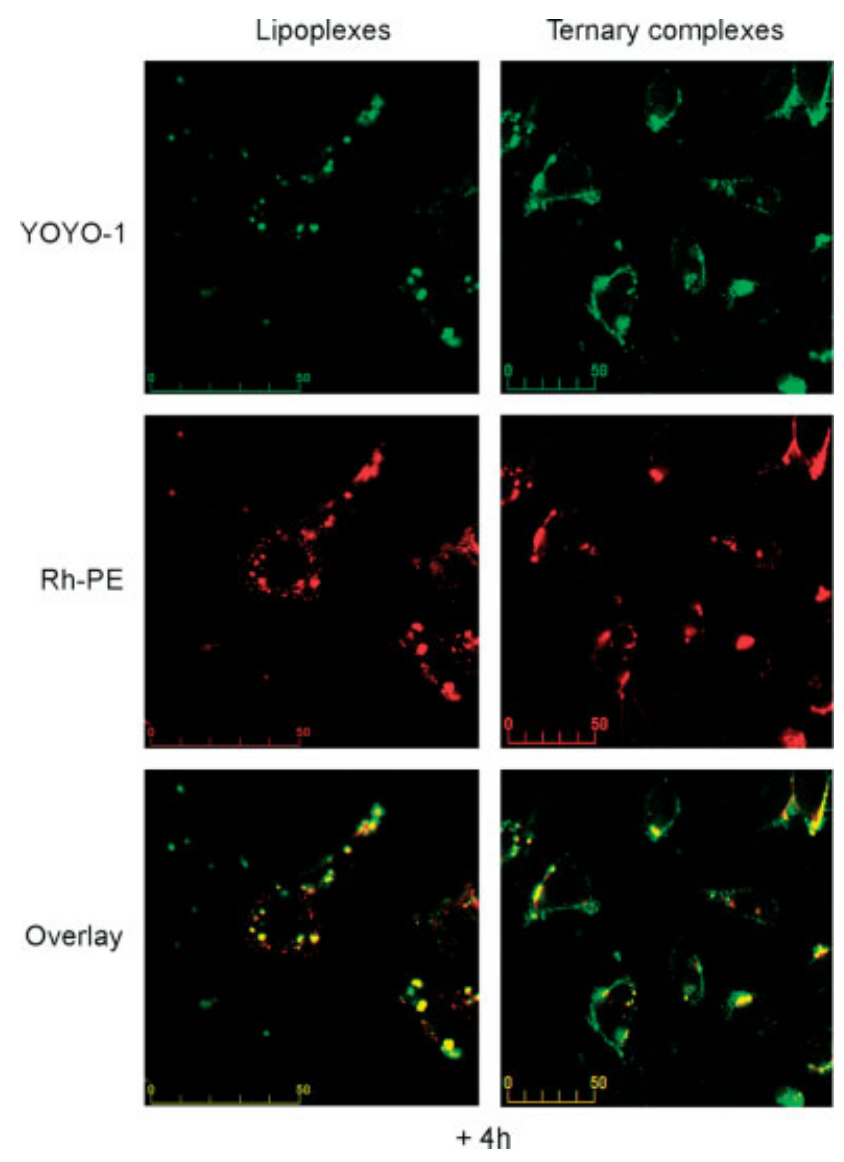

case of the $70 \mathrm{~nm}$ DNA/PEI complexes [43], the ternary complexes may be composed of several DNA molecules. By analogy to lipoplexes, but in contrast to CTAB/DNA complexes, ternary complexes were not dissociated during electrophoresis (Figure 4), suggesting that the ternary complexes were not solubilized by the detergent [44]. Furthermore, the cytotoxicity assays (Figure 9) proved that a significant part of the CTAB molecules remained in the ternary complexes and was not expelled by the binding of cationic liposomes. Moreover, the complexes exhibited a significant decrease in the zeta potential as compared with the corresponding lipoplexes and did not aggregate. In addition, the ternary complexes appear more resistant than lipoplexes to interaction with negatively charged and neutral vesicles (Figures 6 and 7). Finally, in line with the differences in their physicochemical properties,

Figure 10. Internalization of the ternary complexes and lipoplexes. The lipoplexes and ternary complexes were doubly labelled by the DNA bis-intercalating dye, YOYO-1, and the lipid marker, Rh-PE, as described in 'Materials and methods'. L929 cells were incubated with lipoplexes (left panel) or ternary complexes at $r^{\prime}=1$ (right panel) and visualized by confocal microscopy at $4 \mathrm{~h}$ post-transfection. Representative images of YOYO-labelled DNA (green) and Rh-PE-liposomes (red) are shown in the first two rows. Co-localization of YOYO and Rh-PE signals appears in yellow in the overlay pictures. Note the limited number of co-localized signals in the case of ternary complexes. Scale bars represent $50 \mu \mathrm{m}$

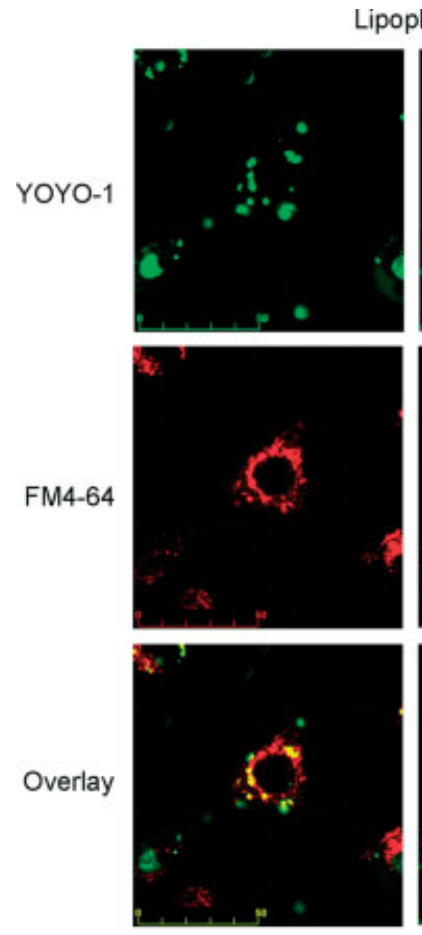

- serum
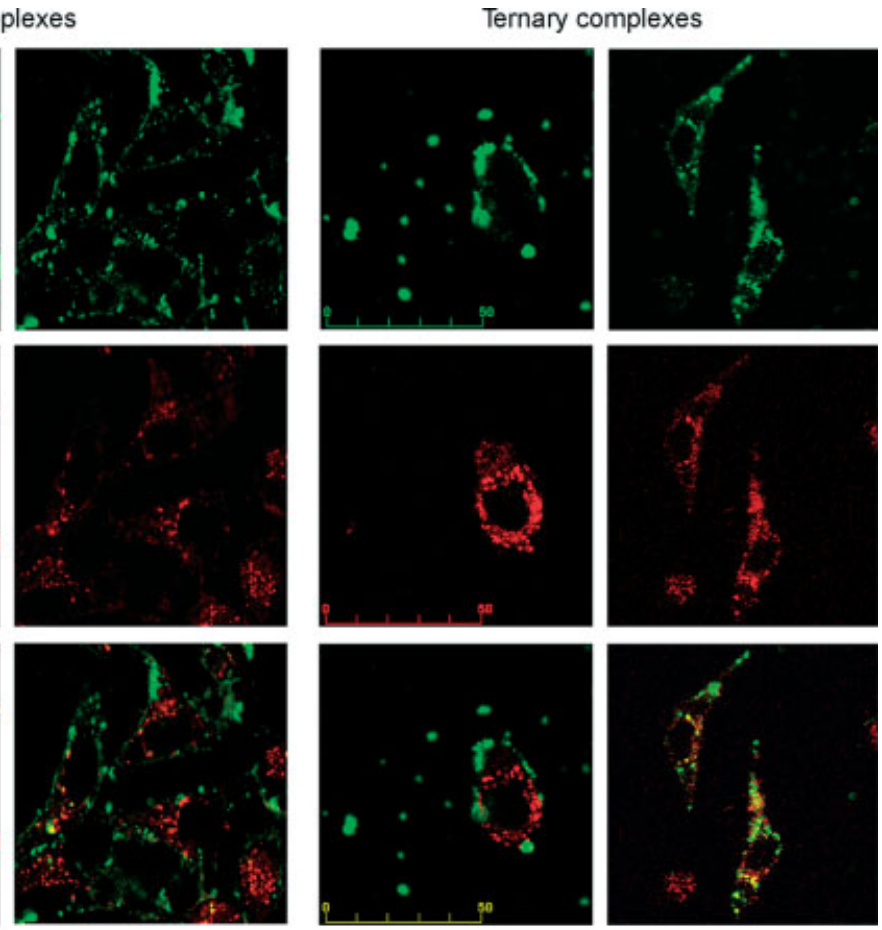

+ serum

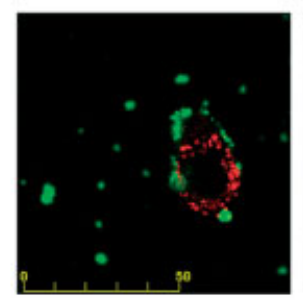

- serum

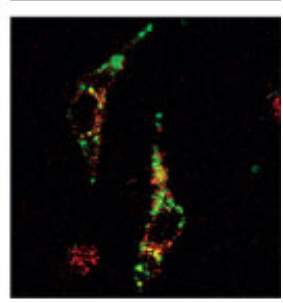

+ serum

Figure 11. Role of endocytosis in the internalization of the ternary complexes and lipoplexes. L929 cells were co-incubated with the endocytosis marker, FM4-64, and YOYO-labelled lipoplexes (left panel) or YOYO-labelled ternary complexes at $r^{\prime}=1$ (right panel) in the absence or presence of $10 \%$ serum. Observations were performed at $4 \mathrm{~h}$ post-transfection by confocal microscopy. Representative images of YOYO-labelled complexes (green) and FM4-64 (red) are shown in the first two rows. Co-localized YOYO and FM4-64 signals appear in yellow in the overlay pictures. Scale bars represent $50 \mu \mathrm{m}$ 
the lipoplexes and ternary complexes exhibit different transfection efficiencies. While the former were found to be more efficient than the ternary complexes in the absence of serum, the reverse behavior was observed in the presence of serum.

As suggested previously [45], both the transfection efficiency and the colloidal stability may be related to the internal organization of the complexes. In this respect, electron microscopy data (Figure 5) indicate that the DMTAP:DOPE/DNA lipoplexes adopt a multilamellar organization in contrast to the inverted hexagonal $\mathrm{H}_{I I}$ structure reported for DOTAP : DOPE/DNA lipoplexes [46]. This discrepancy may be explained by using the dynamic molecular shape concept [47] that predicts the spontaneous curvature of an aqueous lipid dispersion based on the relative surface occupied by the hydrated headgroup versus the cross-section of the alkyl chains. In this respect, while the cylindrical shape (the headgroup area being approximately equal to the hydrophobic tail area) of DOTAP molecules favors the formation of lamellar structures, addition of DOPE molecules with a conical shape (with a smaller headgroup area than tail area) induces a negative natural curvature and promotes the inverted hexagonal phase of the DOTAP:DOPE/DNA lipoplexes. Since the DMTAP molecules have the same headgroup as DOTAP molecules but a smaller and more flexible tail (14 carbons versus 18 carbons), they are thought to induce a positive natural curvature. Accordingly, combination of the opposite shapes of DMTAP and DOPE molecules could lead to a lamellar bilayer by steric complementarity as reported for DOSPA:DOPE/DNA lipoplexes [48]. Since the DMTAP:DOPE/DNA and DOTAP:DOPE/DNA lipoplexes exhibit similar transfection efficiencies (Figure 2 ), this suggests that the intrinsic properties of DMTAP molecules may compensate the unfavorable (in respect with transfection) multilamellar organization adopted by the DMTAP:DOPE/DNA lipoplexes. It may notably be speculated that due to their small hydrophobic tail, the DMTAP molecules provide only a limited stabilization of the multilamellar organization (Figure 7) that favors its dissociation during the intracellular pathway.

For the ternary complexes at $r^{\prime}=1$, the larger volume occupied by the DNA molecules in the multilamellar organization of several complexes (Figure 5B) suggests that the DNA molecules may be packed with detergent molecules bound on them. In addition, the CTAB molecules seem also to affect the general organization of the multilayer since a significant decrease in the number of bilayers was observed in comparison with the corresponding lipoplexes. Moreover, the coexistence of the multilayered complexes with more dense and compact complexes (which are the major particles at higher $r^{\prime}$ values) may be related to the limited affinity of CTAB to DNA. Indeed, at $r^{\prime}=1$, it has been reported that the affinity of CTAB for DNA is not sufficient to saturate all the DNA molecules [10,11] and thus only the dense globular particles may correspond to the interaction of DMTAP : DOPE/DNA lipoplexes with fully saturated DNA molecules. The formation of the highly bent and packed layers in these dense particles may be permitted by the increased fluidity of the lipidic phase induced by the incorporation of the CTAB molecules [49]. Moreover, the monomolecular collapse of DNA by CTAB is expected to induce a large shortening of the DNA gyration radius [50]. Consequently, in contrast to the elongated free DNA molecules, only short planar lamellar lipidic phases are required to sandwich the collapsed CTAB/DNA complexes, enabling the lipid bilayer to bend more readily.

Noticeably, since CTAB molecules are characterized by headgroups that are large relative to their hydrophobic domain [15], they have an inverted cone shape and tend to form micelles in aqueous solution. However, since CTAB molecules at $r^{\prime}=2$ represent only one-seventh of the amphiphile molecules added to the DNA, and since a significant fraction of the CTAB molecules is thought to bind DNA, they are thought to not significantly affect the lamellar organization of the hydrophobic layers in the ternary complexes. This conclusion is in line with the limited lipid mixing (Figure 7) and DNA release observed in the presence of negative vesicles (Figure 6) showing that ternary complexes behave similarly to DOPC-containing lipoplexes which exhibit a lamellar structure [34]. Indeed, lamellar structures have been reported to be much more stable during the interaction with membranes than the inverted hexagonal structure of various DOPE-containing lipoplexes [34]. Moreover, the higher stability of the ternary complexes in respect to the DMTAP : DOPE/DNA lipoplexes during the interaction with either negatively charged or neutral vesicles may tentatively be related to their higher compaction level which reduces the surface of exposed hydrophobic layers. This conclusion is in sharp contrast with the confocal data (Figures 10 and 11) showing that ternary complexes are more destabilized than lipoplexes by the cell membrane in the absence of serum. This suggests that the ternary complexes may be destabilized by the interaction with compounds that are not present in the model vesicles. Likely candidates may be the glycosaminoglycans (GAGs) such as heparan sulfate, since their interaction with lipoplexes has been shown to depend on the structure of the lipoplexes [41].

On the other hand, the higher stability of the ternary complexes in respect to the lipoplexes in the presence of serum, as assessed from their lower dissociation onto the cell membrane (Figure 11), may be related to their initial interaction with serum proteins. By analogy to the data with negatively charged vesicles (Figure 6), the ternary complexes with their highly packed and dense lamellar internal structure are thought to be less destabilized than lipoplexes by the binding to serum proteins. This may be especially true for albumin, which is well known for its colloidal protection properties [51,52]. It follows then that the protein-coated ternary complexes may be more stable than protein-coated lipoplexes to the interaction with GAGs, leading to efficient internalization and transfection. 


\section{Conclusions}

In conclusion, we have shown in the present study that small, monodisperse and highly stable complexes can be obtained by precompaction of DNA with CTAB, followed by addition of cationic lipids. These ternary complexes were found to be less toxic and more efficient than the corresponding lipoplexes in the presence of serum. This higher efficiency was related to the highly dense and bent lamellar structure adopted by these complexes which prevents their dissociation by serum proteins and allows subsequent efficient internalization in the target cells. Additional work is in progress to further characterize the internal structure of the ternary complexes in order to further understand their structure-activity relationship and rationally improve their transfection efficiency.

\section{Acknowledgements}

We thank Jean Serge Rémy for stimulating discussion. This work was supported by the Association Française contre les Myopathies, Association de la Recherche contre le Cancer, Ligue Régionale de la Recherche contre le Cancer, CNRS and Université Louis Pasteur. DL is a fellow from the Ministère de la Recherche et des Technologies.

\section{References}

1. Crystal RG. Transfer of genes to humans: early lessons and obstacles to success. Science 1995; 270: 404-410.

2. Verma IM, Somia N. Gene therapy - promises, problems and prospects. Nature 1997; 389: 239-242.

3. Wisse E, De Zanger RB, Charels K, Van Der Smissen P, McCuskey RS. The liver sieve: considerations concerning the structure and function of endothelial fenestrae, the sinusoidal wall and the space of Disse. Hepatology 1985; 5: 683-692.

4. Sanders NN, De Smedt SC, Van Rompaey E, Simoens P, De Baets F, Demeester J. Cystic fibrosis sputum: a barrier to the transport of nanospheres. Am J Respir Crit Care Med 2000; 162: 1905-1911.

5. Olmsted SS, Padgett JL, Yudin AI, Whaley KJ, Moench TR, Cone RA. Diffusion of macromolecules and virus-like particles in human cervical mucus. Biophys J 2001; 81: 1930-1937.

6. Kolb-Bachofen V, Schlepper-Schafer J, Kolb H. Receptormediated particle uptake by liver macrophages. The galactoseparticle receptor mediates uptake via coated and also non-coated structures. Exp Cell Res 1983; 148: 173-182.

7. Feldherr CM, Akin D. Signal-mediated nuclear transport in proliferating and growth-arrested BALB/c 3T3 cells. $J$ Cell Biol 1991; 115: 933-939.

8. Lukacs GL, Haggie P, Seksek O, Lechardeur D, Freedman N, Verkman AS. Size-dependent DNA mobility in cytoplasm and nucleus. J Biol Chem 2000; 275: 1625-1629.

9. Xu Y, Szoka FC Jr. Mechanism of DNA release from cationic liposome/DNA complexes used in cell transfection. Biochemistry 1996; 35: 5616-5623.

10. Melnikov SM, Sergeyev VG, Yoshikawa K. Discrete coil-globule transition of large DNA induced by cationic surfactant. $J$ Am Chem Soc 1995; 117: 2401-2408.

11. Lleres D, Clamme JP, Dauty E, et al. Investigation of the stability of dimeric cationic surfactant/DNA complexes and their interaction with model membrane systems. Langmuir 2002; 18: 10 340-10 347 .

12. Yoshikawa K. Controlling the higher-order structure of giant DNA molecules. Adv Drug Deliv Rev 2001; 52: 235-244.

13. Dauty E, Remy JS, Blessing T, Behr JP. Dimerizable cationic detergents with a low $\mathrm{cmc}$ condense plasmid DNA into nanometric particles and transfect cells in culture. $J$ Am Chem Soc 2001; 123: 9227-9234.

14. Clamme JP, Bernacchi S, Vuilleumier C, Duportail G, Mely Y. Gene transfer by cationic surfactants is essentially limited by the trapping of the surfactant/DNA complexes onto the cell membrane: a fluorescence investigation. Biochim Biophys Acta 2000; 1467: 347-361.

15. Lleres D, Dauty E, Behr JP, Mely Y, Duportail G. DNA condensation by an oxidizable cationic detergent. Interactions with lipid vesicles. Chem Phys Lipids 2001; 111: 59-71.

16. Pinnaduwage $P$, Schmitt L, Huang L. Use of a quaternary ammonium detergent in liposome mediated DNA transfection of mouse L-cells. Biochim Biophys Acta 1989; 985: 33-37.

17. Blessing T, Remy JS, Behr JP. Monomolecular collapse of plasmid DNA into stable virus-like particles. Proc Natl Acad Sci U S A 1998; 95: 1427-1431.

18. Weibel JM. Thèse de Doctorat, l'Université Louis Pasteur, Paris, France, 1994.

19. Zanta MA, Boussif O, Adib A, Behr JP. In vitro gene delivery to hepatocytes with galactosylated polyethylenimine. Bioconjug Chem 1997; 8: 839-844.

20. Bartlett GR. Phosphorus assay in column chromatography. J Biol Chem 1959; 234: 466-468.

21. Felgner PL, Barenholz Y, Behr JP, et al. Nomenclature for synthetic gene delivery systems. Hum Gene Ther 1997; 8: 511-512.

22. Struck DK, Hoekstra D, Pagano RE. Use of resonance energy transfer to monitor membrane fusion. Biochemistry 1981; 20: 4093-4099.

23. Duzgunes N, Allen TM, Fedor J, Papahadjopoulos D. Lipid mixing during membrane aggregation and fusion: why fusion assays disagree. Biochemistry 1987; 26: 8435-8442.

24. Mosmann T. Rapid colorimetric assay for cellular growth and survival: application to proliferation and cytotoxicity assays. J Immunol Methods 1983; 65: 55-63.

25. Felgner JH, Kumar R, Sridhar CN, et al. Enhanced gene delivery and mechanism studies with a novel series of cationic lipid formulations. J Biol Chem 1994; 269: 2550-2561.

26. Solodin I, Brown CS, Bruno MS, et al. A novel series of amphiphilic imidazolinium compounds for in vitro and in vivo gene delivery. Biochemistry 1995; 34: 13 537-13 544.

27. Farhood H, Serbina N, Huang L. The role of dioleoylphosphatidylethanolamine in cationic liposome mediated gene transfer. Biochim Biophys Acta 1995; 1235: 289-295.

28. Behr JP. Synthetic gene-transfer vectors. Acc Chem Res 1993; 26: 274-278.

29. Felgner PL, Ringold GM. Cationic liposome-mediated transfection. Nature 1989; 337: 387-388.

30. Boussif O, Zanta MA, Behr JP. Optimized galenics improve in vitro gene transfer with cationic molecules up to 1000 -fold. Gene Ther 1996; 3: 1074-1080.

31. Thierry AR, Rabinovich P, Peng B, Mahan LC, Bryant JL, Gallo RC. Characterization of liposome-mediated gene delivery: expression, stability and pharmacokinetics of plasmid DNA. Gene Ther 1997; 4: 226-237.

32. Wiethoff CM, Gill ML, Koe GS, Koe JG, Middaugh CR. The structural organization of cationic lipid-DNA complexes. $J$ Biol Chem 2002; 277: 44980-44987.

33. Radler JO, Koltover I, Salditt T, Safinya CR. Structure of DNAcationic liposome complexes: DNA intercalation in multilamellar membranes in distinct interhelical packing regimes. Science 1997; 275: 810-814.

34. Koltover I, Salditt T, Radler JO, Safinya CR. An inverted hexagonal phase of cationic liposome-DNA complexes related to DNA release and delivery. Science 1998; 281: 78-81.

35. Labat-Moleur F, Steffan AM, Brisson C, et al. An electron microscopy study into the mechanism of gene transfer with lipopolyamines. Gene Ther 1996; 3: 1010-1017.

36. Pitard B, Oudrhiri N, Vigneron JP, et al. Structural characteristics of supramolecular assemblies formed by guanidiniumcholesterol reagents for gene transfection. Proc Natl Acad Sci U S A 1999; 96: 2621-2626.

37. Devaux PF. Static and dynamic lipid asymmetry in cell membranes. Biochemistry 1991; 30: 1163-1173.

38. Harvie P, Wong FM, Bally MB. Characterization of lipid DNA interactions. I. Destabilization of bound lipids and DNA dissociation. Biophys $J$ 1998; 75: 1040-1051.

39. Ogris M, Steinlein P, Kursa M, Mechtler K, Kircheis R, Wagner E. The size of DNA/transferrin-PEI complexes is an important 
factor for gene expression in cultured cells. Gene Ther 1998; 5: $1425-1433$.

40. Wightman L, Kircheis R, Rossler V, et al. Different behavior of branched and linear polyethylenimine for gene delivery in vitro and in vivo. $J$ Gene Med 2001; 3: 362-372.

41. Ruponen M, Ronkko S, Honkakoski P, Pelkonen J, Tammi M, Urtti A. Extracellular glycosaminoglycans modify cellular trafficking of lipoplexes and polyplexes. J Biol Chem 2001; 276: 33 875-33880.

42. Remy-Kristensen A, Clamme JP, Vuilleumier C, Kuhry JG, Mely Y. Role of endocytosis in the transfection of L929 fibroblasts by polyethylenimine/DNA complexes. Biochim Biophys Acta 2001; 1514: 21-32.

43. Clamme JP, Azoulay J, Mely Y. Monitoring of the formation and dissociation of polyethylenimine/DNA complexes by two photon fluorescence correlation spectroscopy. Biophys $J$ 2003; 84: $1960-1968$

44. Trubetskoy VS, Wolff JA, Budker VG. The role of a microscopic colloidally stabilized phase in solubilizing oligoamine-condensed DNA complexes. Biophys J 2003; 84: 1124-1130.

45. Turek J, Dubertret C, Jaslin G, Antonakis K, Scherman D, Pitard B. Formulations which increase the size of lipoplexes prevent serum-associated inhibition of transfection. $J$ Gene Med
2000; $2: 32-40$

46. Safinya CR. Structures of lipid-DNA complexes: supramolecular assembly and gene delivery. Curr Opin Struct Biol 2001; 11: 440-448.

47. Holland JW, Cullis PR, Madden TD. Poly(ethylene glycol)-lipid conjugates promote bilayer formation in mixtures of non-bilayerforming lipids. Biochemistry 1996; 35: 2610-2617.

48. Simberg D, Danino D, Talmon Y, et al. Phase behavior, DNA ordering, and size instability of cationic lipoplexes. Relevance to optimal transfection activity. $J$ Biol Chem 2001; 276: 47 453-47459.

49. Inoue T. Interaction of surfactants with phospholipid vesicles. In Vesicles, vol. 62. Rosoff M (ed). Marcel Dekker: New York, 1996.

50. Bloomfield VA, Crothers DM, Tinocco IJ. Nucleic Acids, Structures, Properties, and Functions. Sausalito: CA, 2000.

51. Verrecchia T, Huve P, Bazile D, Veillard M, Spenlehauer G, Couvreur P. Adsorption/desorption of human serum albumin at the surface of poly(lactic acid) nanoparticles prepared by a solvent evaporation process. J Biomed Mater Res 1993; 27: 1019-1028.

52. Boukhnikachvili T, Aguerre-Chariol O, Airiau M, Lesieur S, Ollivon M, Vacus J. Structure of in-serum transfecting DNAcationic lipid complexes. FEBS Lett 1997; 409: 188-194. 